\title{
A ERUPÇÃO VULCÂNICA DE 2014/15 NA ILHA DO FOGO CABO VERDE E SUAS PRINCIPAIS CONSEQUÊNCIAS
}

\section{THE VOLCANIC ERUPTION OF 2014/15 ON FOGO ISLAND CAPE VERDE AND THE MAIN EFFECTS}

\author{
Sónia Silva* \\ Vera Alfama** \\ Nadir Cardoso***
}

\section{Introdução}

0 arquipélago de Cabo Verde apresenta condições naturais adversas e está sujeito a uma grande diversidade de riscos naturais. Para além dos riscos sísmico e vulcânicos, praticamente limitados às ilhas da Brava, no primeiro caso, e do Fogo, nos dois casos, e dos riscos de seca, desertificação e erosão dos solos, ligados à localização geográfica e climática do arquipélago, outros riscos naturais, tais como cheias/inundações, movimentos de vertentes, tempestades e, mes- mo, os incêndios florestais têm, frequentemente, manifestações que se traduzem em fortes impactes económicos e sociais (MONTEIRO et al., 2009).

Chã das Caldeiras, onde se encontra o único vulcão ativo com erupções históricas no país, localiza-se no Município de Santa Catarina,que representa um dos três municípios existentes na ilha do Fogo, Cabo Verde.Este município confronta a norte com o município dos Mosteiros, a oeste com o município de São Filipe, e a sul e este com o oceano Atlântico, cobrindo uma área de

\footnotetext{
* Licenciada em Geologia - Ramo Científico pela Universidade de Lisboa, Mestre em Geociências pela Universidade de Coimbra, Doutora em Engenharia Geológica, especialidade na área de Geologia do Ambiente e do Ordenamento do Território na Universidade de Coimbra, vinculada à Universidade do Cabo Verde - Uni-CV (Praia/Cabo Verde).. sonia.silva@adm.unicv.edu.cv.

** Licenciada em Ensino de Biologia e Geologia pela Universidade de Évora, Mestre em Património Geológico e Geoconservação pela Universidade do Minho, Doutoranda em Geologia, especialidade na área de Vulcanologia e Avaliação Riscos Geológicos na Universidade dos Açores, vinculada à Universidade do Cabo Verde - Uni-CV (Praia/Cabo Verde).. vera.alfama@adm.unicv.edu.cv.

*** Licenciada em Química pela Universidade de Cabo Verde (Agosto 2009). Desde Novembro de 2009 é Docente Assistente, é atualmente responsável pela gestão dos laboratórios de Química da Uni-CV (Praia/ Cabo Verde).nadir.cardoso@docente.unicv.edu.cv.
} 
cerca de $154 \mathrm{Km}^{2}$, equivalente a 33,7\% da área da ilha. É um Município composto por oito (8) localidades e tem a sua sede em Cova Figueira (PDM, 2010).

As formas de relevo neste município são constituídas, fundamentalmente, por mantos e material piroclástico intercalado, de natureza essencialmente basáltica, de grande extensão e espessura (MACHADO; ASSNUNÇÃO, 1965; ASSUNÇÃO et al., 1967). A formação geológica predominante são os nefelinitos (55\%) seguido de cones de acumulação de escórias que ocupa 17\% da área do município. As rochas sedimentares têm pouca representatividade, podendo serencontradas formações tais como areia da praia e depósitos torrenciais ou de vertentes.Com base em estudos realizados e no modelo estrutural da ilha do Fogo foi possivel a identificação e caracterização das principais estruturas de origem vulcânica, tectónica e gravítica que permitiram a identificação de três sistemas de falhas principais, com direções NW-SE a WNW-ESE, N-S e NNE-SSW (SILVEIRA et al., 1997).

Com mais de 40 mil habitantes (INE, 2010), a Ilha do Fogo comporta um elevado risco vulcânico, pelo que se torna necessário promover estratégias orientadas para a minimização dos impactos de futuras ocorrências.

A ocorrência das últimas 7 erupções em Chã das Caldeiras (a partir do Século XIX) demonstra uma forte probabilidade defuturas erupções vulcânicas vierem a ocorrer nesta área. Um aspeto muito peculiar das erupções é que se têm dado em crateras pré-existentes (e.g Pico de 1995) ou através de uma fissura (exemplo Pico de 2014/15).
Osperigos vulcânicos que se tem observado na ilha do Fogo estão associados aos produtos vulcânicos emitidos, como piroclastos, lavas e gases, associados aos perigos sísmico e de movimentos de vertente.

Em Santa Catarina por se tratar de um município situado em áreas de potenciais riscos vulcânico, sísmico e de movimento de vertente (devido ao elevado declive), o sector responsável pela proteção civil deverá dispensar uma atenção especial ao definir estratégias e recursos para situações de emergência para este município.

Neste trabalho são feitas referências à caraterização da Erupção Vulcânica de 2014/15 bem como às principais consequências ambientais e socioecónomicas provocadas pela ocorrência deste fenómeno natural.

\section{Caraterização da Erupção Vulcânica}

A atividade vulcânica teve início no dia de 23 de novembro, por volta das 9:45h, tendo sido precedida por abalos sísmicos sentidos desde 20 de novembro até minutos antes da erupção. Os sismos foram sentidos nas localidades de Chã das Caldeiras, no dia 20, e em Cova Figueira, no dia 21. Na Chã das Caldeiras ocorreram mais sismos de forte intensidade no dia 22 de Novembro, pelas 20h, e no dia 23 de novembro,à $01 \mathrm{~h}$. A erupção ocorreu ao longo de uma fissura SSW-NNE no flanco leste do Pico Novo, com formação de quatro crateras eruptivas com emissão de gases, piroclastos e lavas (Fig. 1a e b). A queda de cinzas ocorreu na Chã das Caldeiras, S. Filipe, Cova Figueira, Patim, Monte Grande, e nas ilhas Brava e S. Vicente. 
a) Aspeto da erupção nas primeiras horas

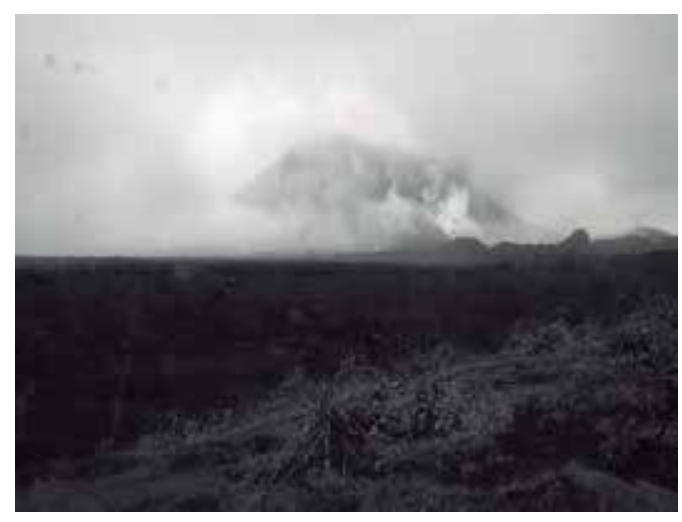

A atividade vulcânica ocorreu, provavelmente, devido à reativação da falha do Monte Beco (a mesma que deu origem à erupção vulcânica de 1995). 0 estilo eruptivo do tipo estromboliano iniciou-se com uma fase explosiva caracterizada com a libertação de gases e piroclastos (cinzas), formando uma coluna eruptiva com cerca de $6 \mathrm{~km}$. As primeiras emissões de fluxos de lavas foram inicialmente do tipo pahoehoe mudando de seguida para lavas $a a$, tendose deslocado entre o Monte Cova Tina e o Monte Beco. Formaram-se mais três crateras eruptivas com emissões estrombolianas (explosões de gases, piroclastos e escoamento de lavas). Desenvolveram-se ainda mais duas frentes de escoadas de lavas, uma com sentido aos povoados Ilhéu de Losna/Cova Tina e outra frente em direcção à localidade de Portela.

As lavas cortaram a estrada principal por volta das $12 \mathrm{~h}$. De seguida, formaram-se cerca de quatro crateras eruptivas em círculo ao longo da fissura, no lado este do Pico Novo (cone eruptivo formado na erupção de 1995). A atividade explosiva evoluiu em cinco crateras eruptivas. 0 terceiro fluxo de b) Aspeto do avanço das lavas na localidade de Portela.

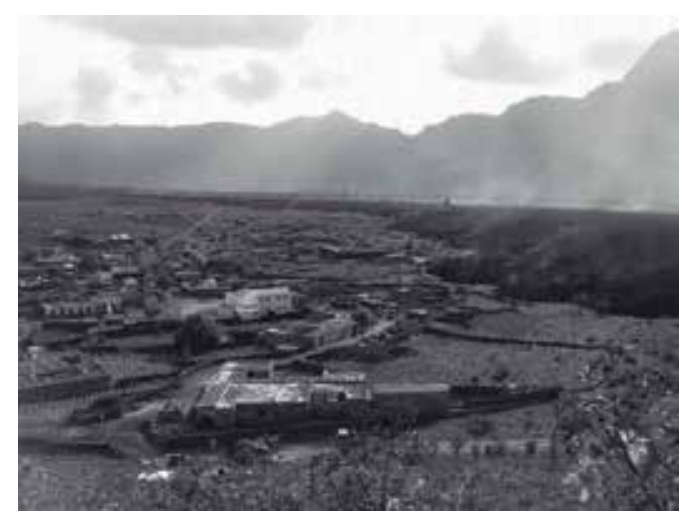

lavas aa alcançou a localidade de Portela. 0 avanço das lavas em Portela deu-se com velocidades médias de 30-50 metros/hora, decrescendo para 8-13 metros/hora até 1-3 metros/hora. As lavas seguiram-se em duas direcções, uma na direcção SW, em direcção de Cova Tina, do tipo $a a$, tendo cortado a estrada alternativa às 22h15. Outro fluxo de lavas do tipo pahoehoe, que seguiu na direcção de Monte Beco, chegou a atingir espessuras de 5 metros. Cerca das 19h30, os dois fluxos de lavas já apresentavam cerca de $1,5 \mathrm{~km}$, e às $21 \mathrm{~h} 50$, com cerca de 1,8 $\mathrm{km}$ de avanço. Nesta fase, particularmente intensa, violentas explosões projetaram piroclastos de maiores dimensões (bombas e escórias) atingindo altitudes de 4 metros.

No dia seguinte (24 de novembro), mantiveram-se as explosões com a formação de seis crateras eruptivas alinhadas na direcção NE-SW, com emissão de gases e produtos piroclásticos formando a coluna eruptiva que apresentava altura considerável. No dia 26 de novembro às $6 \mathrm{~h} 10$, as lavas atingiram as imediações da primeira casa a sul da localidade de Portela, sendo a velocidade das lavas de 2 metros/hora e com altura média 
de 7-8 metros. No período da tarde, 15 casas já tinham sido destruídas, para além de algumas cisternas, currais de animais e áreas de cultivo. No dia 2 de Dezembro por volta das $4 \mathrm{~h}$ da manhã aumentou a velocidade do fluxo das escoadas de lava, tendo estas alcançado o centro da Portela, destruindo várias casas, a sede do Parque Natural do Fogo, a Escola Básica, algumas cisternas e currais, duas unidades hoteleiras, o Posto Sanitário e a Delegação da Câmara Municipal.

No dia 7 de dezembro houve um aumento do fluxo de lavas que continuaram a provocar destruição, por volta das 8 h45 em Portela e Bangaeira (Fig. 2a e b). Estes fluxos atingiram uma largura de cerca de 200-250 metros e altura de cerca de 2,5 a 3 metros, tendo destruído as igrejas Adventista e Católica, e parte da adega Chã. A frente das lavas apresentavam-se muito fluída tendo criado duas ramificações à entrada e a meio de Bangaeira, com largura total de 500 metros. Cerca de 50\% deste povoado foi destruído no período da manhã. A velocidade estimada das lavas foi de 20-30 metros/minuto. A coluna eruptiva foi apresentando altura e aspecto diferente ao longo da erupção. As observações efectuadas diariamente a partir do Monte Beco permitiram ver que foi formado um pequeno canal na base do cone originado e que ia alimentando as escoadas de lava.

Figura 2 - Aspeto das escoadas lávicas que destruíram as localidades de Portela e Bangaeira:

a) Aspeto das escoadas de lavas junto à Adega Chã em Portela;

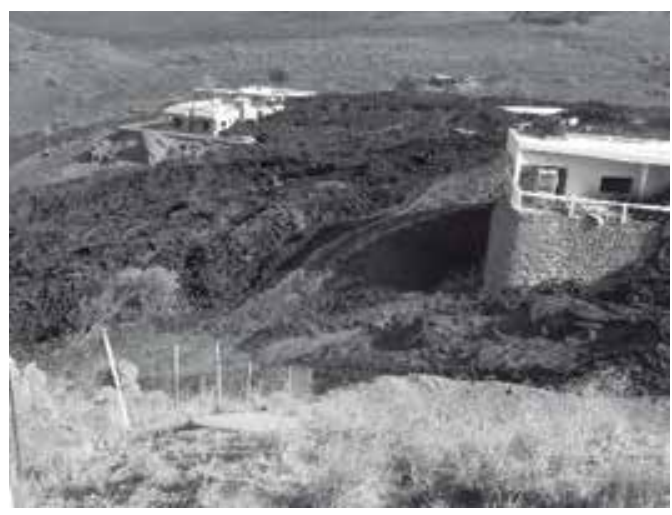

Entre os dias 10 e 13 de dezembro o vulcão apresentou uma ligeira diminuição no escoamento de lavas observando a formação das mesmas através de um pequeno canal, na base do cone formado. As lavas em Portela e Bangaeira mantinham-se praticamente estagnadas com uma velocidade reduzida. A 14 de dezembro verificou-se que a actividade vulcânica deixou o período de relativa acal- b) Aspeto da destruição ocorrida e Bangaeira.

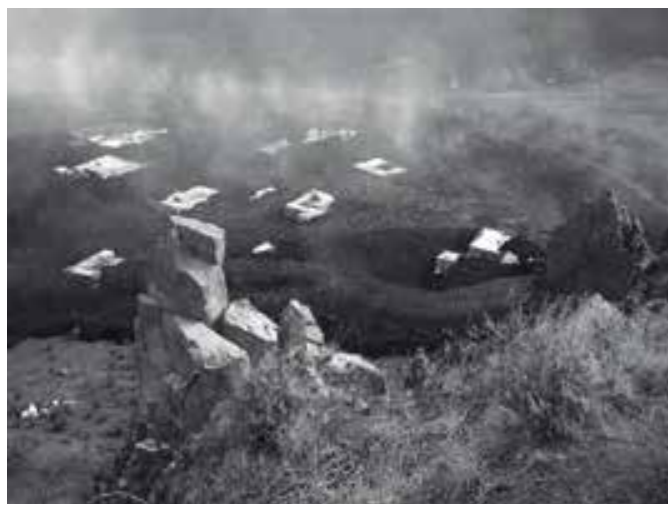

mia e mudou de comportamento tendo sido activadas 6 frentes de lavas que apresentavam extensão e velocidades consideráveis.

No dia 16 de dezembro, uma escoada lávica muito fluída desviou-se paraMonte Saia e para o pequeno povoado de Ilhéu de Losna (Fig. 3a) tendo atingido esta localidade na madrugada do dia 18 de dezembro, começando por soterrar os campos de culti- 
vo e as primeiras casas. Às $8 \mathrm{~h}$ do dia 19 de dezembro, a escoada lávica já tinha atingido algumas casas em Ilhéu de Losna e a Adega Sodade.A 20 de dezembro, em Ilhéu de Losna, a escoada ativa ramificou-se em duas frentes contornando uma pequena elevação, que se canalizaram em pequenas linhas de água próximas a este cone. A única estrada alternativa de ligação a Portela foi cortada por volta das $19 \mathrm{~h}$ na localidade de Ilhéu de Losna. Todas as casas do lado norte em Ilhéu de Losna foram atingidas pelas lavas a 22 de dezembro (Fig. 3b).

Figura 3 - Escoada lávica em Ilhéu de Losna:

a)especto da fluidez da lava;

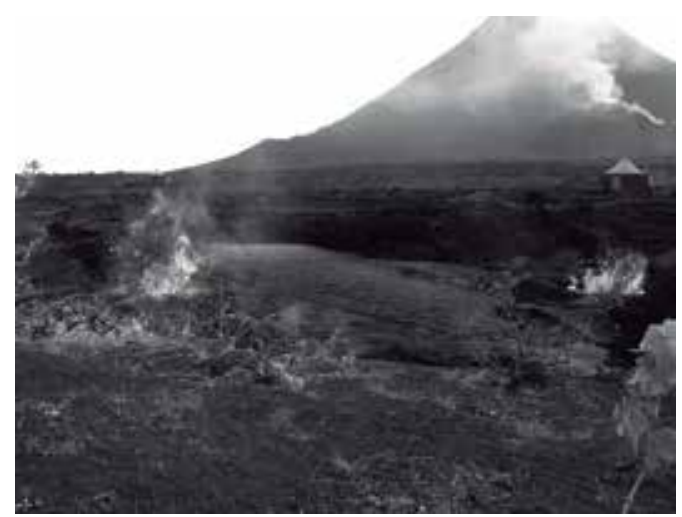

No dia 5 de janeiro de 2015, por volta das $17 \mathrm{~h}$, iniciaram-se fortes explosões seguidas de estrondos com emissão de gases e cinzas projetadas através de uma coluna eruptiva que atingiu uma altura de aproximadamente $1.500 \mathrm{~m}$, tendo esta sido observada em S. Filipe. Na base do cone vulcânico, reiniciou-se a emissão de lavas e observou-se que a distância percorrida pelas escoadas foi de cerca de $50 \mathrm{~m}$ de extensão, com direcção para sul, ou seja, deslocando-se sobre a primeira escoada que se dirigiu para Cova Tina no primeiro dia de erupção vulcânica que continuou ativa até o dia 26 de janeiro.

Entre os dias 20 a 23 de janeiro, houve um incremento da atividade eruptiva que indicou a ocorrência da fase explosiva ca- b) aspeto da destruição provocada pelas escoadas lávicas neste povoado.

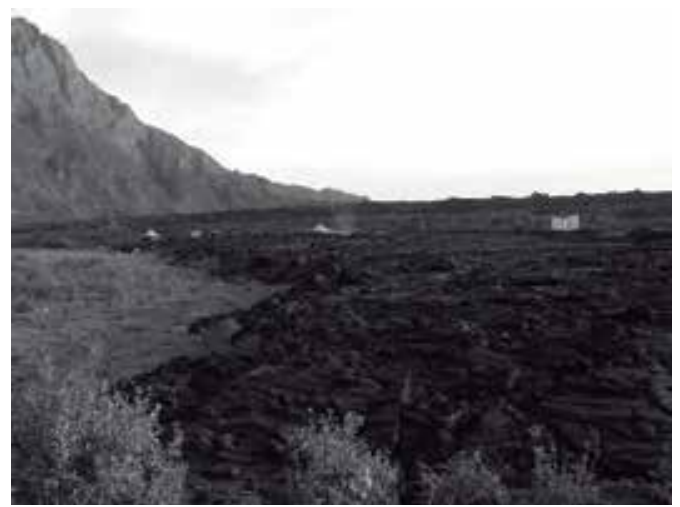

racterizada pela emissão de gases e cinzas. No dia 7 de fevereiro de 2015, ocorreram várias explosões que variavam de intensidade e acompanhadas por fortes ruídos ou estrondos. A partir do dia 8 de fevereiro, não foi observada nenhuma atividade eruptiva e foi dada como terminada a erupção.

\section{Principais consequências}

No dia 23 de novembro de 2014, 19 anos após a ocorrência da última erupção, teve início o mais recente episódio da história vulcânica da ilha do Fogo. Esta erupção decorreu durante 77 dias, tendo terminado a 7 de fevereiro de 2015. Esta erupção vulcânica na ilha do Fogo teve consequências tanto ambientais como socioeconómicas. 
Ao entrarem em atividade, os efeitos dos vulcões representam um grande risco para os moradores que vivem nas proximidades dessas erupções, devido à produção de produtos vulcânicos como a emissão de escoadas lávicas, de piroclastos (bombas, lapilli e cinzas), a libertação dos gases, dentre outros. As lavas expelidas podem destruir tudo o que encontrar no seu caminho, enquanto os piroclastos, principalmente as cinzas, e os gases vulcânicos representam riscos para a saúde humana, que representam os impactos imediatos e diretos das erupções vulcânicas. No entanto, existem consequências indiretas, sendo ambientais, sociais, económicas e culturais.

As escoadas lávicas não representam grande ameaça para as vidas humanas (BLONG, 1984), permitindo normalmente a evacuação atempada das populações, sendo, no entanto, frequentes os avultados danos em propriedades, infraestruturas (DUNCAN et al., 1981, 1996) e na capacidade produtiva, podendo esta última situação ser particularmente dramática em países com menores recursos (WALLENSTEIN et al., 1997). 0 perigo associado à queda de cinzas está relacionada à acção do vento, principalmente com o colapso de edifícios e de infraestruturas (B00TH et al., 1983; BLONG, 1984), à inutilização de campos de cultivo e a problemas de saúde pública, nomeadamente de infeções da vista, dos sistemas respiratório e digestivo (GASPAR et al., 1995). São inúmeras as referências a problemas relacionados com a segurança de aeronaves que voem através de nuvens de cinzas. Estes problemas podem ser particularmente dramáticos numa ilha, pois podem condicionar de modo determinante as ações de evacuação e de salvamento, ou mesmo do transporte de meios de socorro e de logística para as áreas afetadas (WAL-
LENSTEIN, 1999). A cinza vulcânica é altamente prejudicial para a economia porque cobre tudo, infiltra-se por todas as aberturas e é altamente abrasiva.

A libertação de gases vulcânicos assume especial relevo quando as emanações se situam em zonas deprimidas, como é o caso dos vales, das caldeiras e das crateras, ou em espaços pouco arejados, como no interior de grutas, condições naturalmente propícias à acumulação de gases, que podem, assim, atingir concentrações muito superiores às admissiveis para a vida (GASPAR, 1996). Em qualquer das situações, as condições atmosféricas são determinantes no modo de dispersão dos gases e consequentemente na definição das áreas afetadas. Em certas concentrações e consoante o seu grau de toxicidade, os gases vulcânicos são nocivos para a saúde pública, sendo muitas vezes responsáveis pela morte de pessoas e animais, assim como pela ocorrência de lesões ao nível do cérebro, do sistema respiratório, da vista e da pele. Adicionalmente, podem originar mortes indiretas em resultado da ingestão de produtos contaminados e determinar a destruição da comunidade vegetal (BLONG, 1984; CRANDELL et al., 1984; BAXTER e KAPILA, 1989; BAXTER, 1994).

\subsection{Consequências socioeconómicas}

A primeira consequência socioeconómica foi o corte das estradas, principal e alternativa, em Chã das Caldeiras no primeiro dia da erupção poucas horas após o seu início. Servida apenas por uma via pavimentada que acedia às povoações de Portela e Bangaeira e por uma via alternativa, a acessibilidade foi drasticamente reduzida logo no primeiro dia bem, devido à sua interrupção junto dos focos emissores. 
No primeiro dia da erupção, os residentes de Chã das Caldeiras fizeram uma auto -evacuação espontaneamente, retornando quando o fluxo de lava parou no dia seguinte. As primeiras ações de respostas das autoridades de proteção civil após o início da erupção vulcânica foram desenvolvidas pelos serviços municipais de proteção civil, sob orientação direta das câmaras municipais e iniciaram a evacuação dos habitantes da Chã das Caldeiras (Fig.4). Conforme as informações, iniciou-se a evacuação fracionada de Chã das Caldeiras: primeiro os velhos, crianças, grávidas e deficientes. Com a erupção contínua a 25 de novembro, as autoridades da Proteção Civil implementaram a evacuação de todos os moradores, limitando ainda mais o acesso a Chã das Caldeiras (OLIVEIRA, 2015). Algumas pessoas recusaram-se a sair, mas acabaram por fazê-lo dias depois, quando a erupção começou a destruir as primeiras casas.

Figura 4 - Evacuação da população de Chã das Caldeiras (cortesia de Saulo Montrond da Greenstudios).
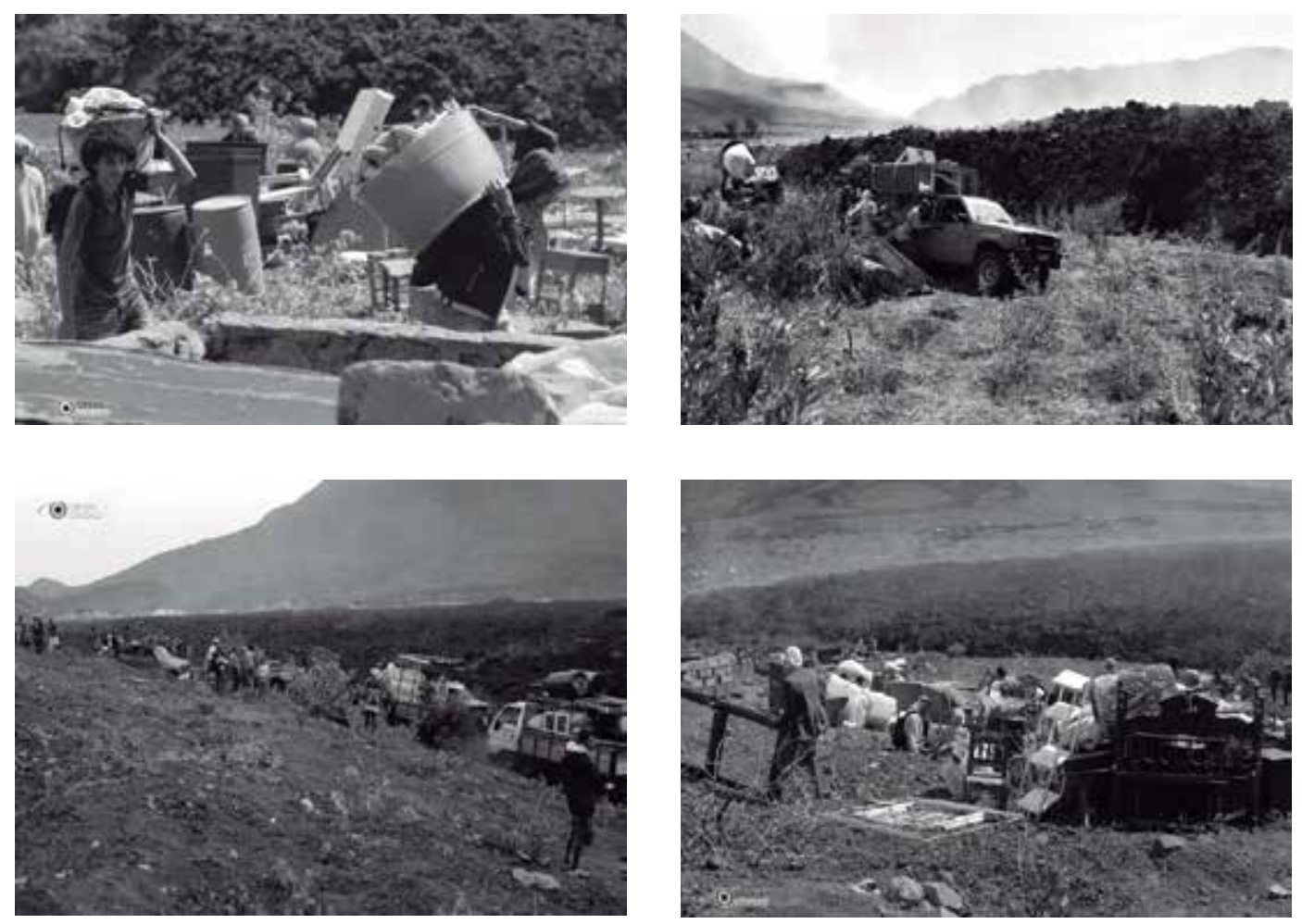

Da população evacuada, faziam parte 929 pessoas, com cerca de 266 famílias deslocadas (251 crianças e 24 idosos) que foram alojadas em 3 Centros de Acolhi- mento - Achada Furna, Monte Grande e Mosteiros, tendo parte (147) sido acolhidas em casa de familiares na cidade de S. Filipe (CORREIA, 2015; Fig. 5). 
a) Campo de acolhimento dos Mosteiros;

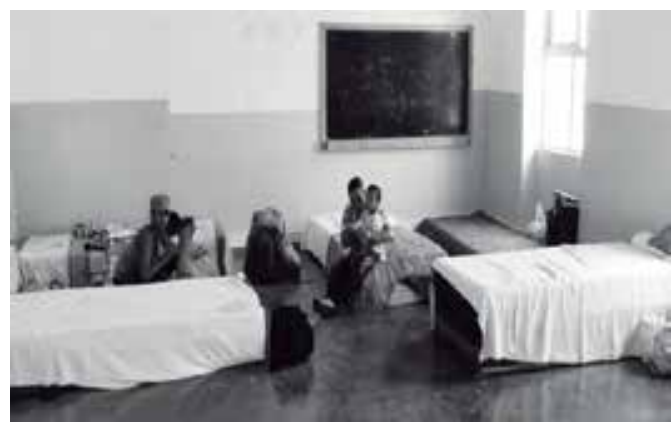

c) Campo de acolhimento em Achada Furna;

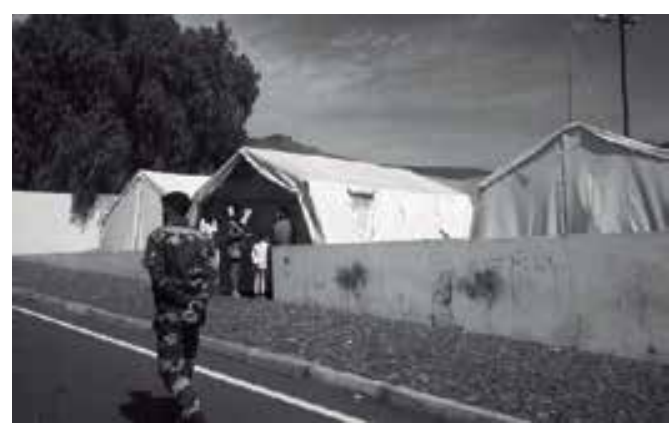

Em Achada Furna, quatro famílias permaneceram numa escola, em tendas, enquanto as demais em 40 unidades unifamiliares, perfazendo um total de 404 pessoas deslocadas que precisaram de assistência. Em Monte Grande, 360 pessoas estão vivendo em 70 unidades unifamiliares; 11 mulheres grávidas estavam entre a população afetada. Em Mosteiros, 165 pessoas estiveram abrigadas num antigo prédio da escola. Em São Felipe, 147 pessoas vivem com famílias de acolhimento e recebem assistência na forma de cestas básicas. Poucas semanas após a sua instalação, os Centros de Acolhimento foram desativados, em primeiro lugar os de Monte Grande e Achada Furna e por fim dos Mosteiros, com a b) Campo de acolhimento em Achada Furna;

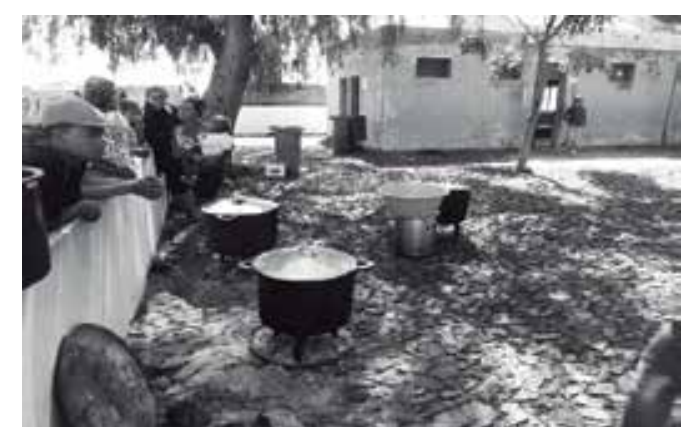

d) Casas construídas na erupção de 1995 em Monte Grande.

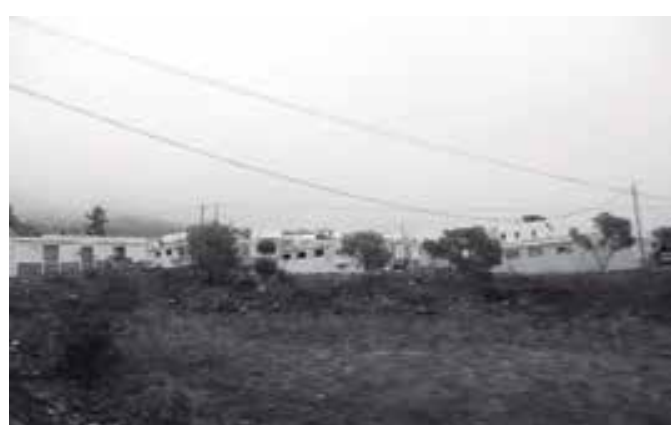

transferência das famílias deslocadas para habitações unifamiliares, algumas arrendadas (GRF, 2015).

As lavas provocaram a destruição quase total de 3 povoados: Portela, Bangaeira e Ilhéu de Losna, destruíram mais de 230 edificações, cobriram cerca 420 hectares de terra e destruíram aproximadamente 120 hectares de terreno agrícola, afetando sobremaneira a vida nesta área da ilha. Embora não tivesse havido perda de vidas, os prejuízos materiais foram avultados, destacando-se o desaparecimento de três aldeias (Portela, Bangaeira e Ilhéu de Losna) e de importantes áreas agrícolas; a destruição de infraestruturas (posto sanitário, duas igrejas, delegação da Câmara Municipal de 
Santa Catarina, unidades hoteleiras, escola do Ensino Básico Integrado, duas adegas, e a sede do parque natural) e equipamentos e o isolamento dos núcleos populacionais mais importantes.

\subsection{Impactos na saúde pública}

Ao longo da erupção foram libertados e mesurados alguns tipos de gases vulcânicos como: Dióxido de Carbono $\left(\mathrm{CO}_{2}\right)$, Dióxido de Enxofre $\left(\mathrm{SO}_{2}\right)$, Ácido Sulfídrico $\left(\mathrm{H}_{2} \mathrm{~S}\right)$, Radão (Rn), Vapor de Água $\left(\mathrm{H}_{2} \mathrm{O}\right)$.

Os gases expelidos nesta erupção e que são mais perigosos para a saúde pública são o dióxido de carbono e o dióxido de enxofre. Tanto um como outro são gases incolores, mas enquanto o $\mathrm{CO}_{2}$ é inodoro, o $\mathrm{SO}_{2}$ possui um odor forte e característico. $0 \mathrm{CO}_{2}$ não representa perigo direto a vida quando libertado em baixas concentrações. No entanto, é mais pesado do que o ar, pode, assim, fluir como uma corrente de densidade para áreas de relevo baixo, aumentando a sua concentração e asfixiando qualquer ser vivo, sendo letal. Foram feitas medições pontuais de $\mathrm{CO}_{2}$, tendo-se feito, no entanto, medições de $\mathrm{SO}_{2}$ diariamente, ao longo da erupção.

$\mathrm{O}$ efeito do $\mathrm{SO}_{2}$ sobre pessoas ou ambiente depende: da quantidade de gases que um vulcão emite para a atmosfera; se os gases são injetados na troposfera ou estratosfera e da direção dos ventos (regionais ou globais) e outras condições meteorológicas (e.g. ocorrência de nevoeiro) que dispersa os gases (ALFAMA et al., 2015). A prolongada exposição a baixas concentrações pode ser perigosa para pessoas com problemas cardiopulmonares preexistentes. A Organização Mundial de Saúde recomenda a concentração de $\mathrm{SO}_{2}$ não maior que $0,5 \mathrm{ppm}$ sobre 24 horas de máxima exposição. De salientar que o maior valor de $\mathrm{SO}_{2}$ registado em todo processo eruptivo na ilha do Fogo foi de 11.100 toneladas por dia (BARRANCOS et al., 2015), e seu cheiro foi sentido nas ilhas do Fogo, Brava, S. Vicente e S. Nicolau.

$\mathrm{Na}$ população local, foram registados alguns casos de problemas respiratórios, tosse; irritação no nariz e na garganta provocando tosse intensa e dificuldade respiratória, bem como a irritação nos olhos e alergias na pele.

\subsection{Impactos ambientais}

A queda de cinzas foi outro produto que provocou alguns impactos ambientais nos povoados locais. A queda de cinzas e poeiras ocorreu sobretudo nas duas primeiras semanas, tendo sido notória, nos primeiros dias da erupção, a acumulação de cinzas em algumas localidades como em Monte Grande, S. Filipe entre outras.

Normalmente entre novembro e março há ocorrência de ventos fortes em Cabo Verde. Tendo em conta a época que ocorreu a erupção as condições meteorológicas permitiram a ocorrência de ventos. Essas condições meteorológicas propiciaram o desenvolvimento de plumas verticais e a dissolução e dispersão dos gases e cinzas. A coluna eruptiva (formada por cinzas e gases) manteve-se ininterrupta ao longo da erupção e foi mudando de direcção de dispersão consoante a direcção dos ventos e terá atingido a altura máxima de $6 \mathrm{~km}$. A dispersão das cinzas atingiu as ilhas do norte do arquipélago, particularmente $\mathrm{S}$. Vicente e S. Nicolau. A queda de cinzas provocou alguns problemas económicos como a interrupção dos voos para a ilha do Fogo e para as ilhas do norte referidas, o estrago de culturas em algumas localidades da ilha, particularmente em Chã das Caldeiras, no norte e na região leste da ilha. 
Convém realçar que a queda de cinzas, a emissão de gases vulcânicos e o escoamento das lavas são aspetos a considerar em caso de avaliação dos riscos vulcânicos nesta ilha devido às potenciais consequências em temos materiais e de saúde pública.

\section{Conclusões}

A erupção de 2014/2015 na Ilha do Fogo foi precedida nos quatro dias antes por alguma sismicidade premonitória, sentida pela população de Chã das Caldeiras e de Cova Figueira. Os abalos mais fortes ocorreram no dia anterior e no próprio dia do início da erupção.Ao longo da erupção, o evento apresentou características estrombolianas, com efusão de lavas e explosões de piroclastos e gases. Os primeiros derrames foram do tipo pahoehoe, mas o grande volume de lava emitido apresentou características $a a$. A comparação com os produtos emitidos em erupções históricas anteriores mostra que se tratou de um evento semelhante aos restantes, localizado no sopé do Vulcão do Pico, apresentando inicialmente características fissurais para se centrar num centro eruptivo com a continuação da erupção.

Como se verificou em erupções anteriores, Chã das Caldeiras foi de novo afetada durante a erupção de 2014/15, mas agora com prejuízos materiais avultados, face a uma já considerável ocupação humana. Desapareceram três aldeias (Portela, Bangaeira e Ilhéu de Losna) e foram destruídas várias infraestruturas, habitações, campos de cultivo para além do facto de as localidades terem sido isoladas desde o primeiro dia devido ao corte das estradas principal e alternativa. Perante o perigo de eminente de serem ocupadas pelas lavas ou afetados por gases tóxicos, foi necessário proceder à evacuação dos seus habitantes.Esta erupção teve vários impactos nas populações locais tais como sociais, económicos e ambientais.

Urge tomar consciência do elevado risco vulcânico que existe em Chã das Caldeiras, dada a recorrência de erupções históricas neste sector da ilha. Em futuras erupções esta área fica, assim, sujeita aos elementos de risco vulcânico mais frequentes como a ocupação por lavas, a queda de material piroclástico (principalmente cinzas) ou a invasão por gases tóxicos.

Perante este cenário é necessário reavaliar o ordenamento do território e prever medidas de proteção civil. É urgente ponderar sobre as condições de ocupação e de habitabilidade desta área, melhorar as condições de acessibilidade, de modo a criar vias alternativas, e implementar medidas preventivas, sobretudo nas áreas de maior suscetibilidade de serem atingidas por vários elementos de risco vulcânico considerados.

\section{Referências}

ALFAMA,V.; RODRIGUES, H.; MOTA, 0.; SILVA, S.; CARDOSO, N.Impactos da Erupção Vulcânica sobre a Saúde Humana. Fórum para a Reconstrução do Fogo. São Filipe, Fogo, 2 e 3 Março de 2015.

ASSUNÇÃO, C.F.T.; MACHADO, F.; SILVA, L.C. Petrologia e vulcanismo da Ilha do Fogo (Cabo Verde). Garcia de Orta,15, 1, 1967. pp. 99-110.

BARRANCOS, J.; DIONIS, S.; QUEVEDO, R.; FERNANDES, P.; RODRÍGUEZ, F.;

PÉREZ, N.; SILVA, S.; CARDOSO, N.; HERNÁNDEZ, P.; MELIÁN, G.; PADRÓN, E.; PADILLA, G.; ASENSIO-RAMOS, M.; CALVO, D.; SEMEDO, H.; ALFAMA, V.Sulphurdioxide $\left(\mathrm{SO}_{2}\right)$ emissionsduringthe 2014-15 Fogo eruption, Cape Verde. Geophysical Research Abstracts. Vol. 17, 2015. EGU General Assembly, 2015. 
BAXTER, P.; KAPILA, M. Acute health impact of the gas release at Lake Nyos, Cameroon, 1986. J. Volcanol. Geotherm. Res., 39, 1989. p. 265-275.

BAXTER, P. Case studies: Health aspects of volcanic activity. European school of climatology and natural hazards: course on the mitigation of volcanic hazards, 12-18 June,1994. 8p.

BLONG, R.Volcanic hazards. A sourcebook on the effects of eruptions. Academic Press, 1984.

BOOTH, B.; CROASDALE, R.; WALKER, G. Volcanic hazard on São Miguel, Azores. In: TAZIEFF, H.; SABROUX, J. C. (Eds.), Forecasting volcanic events. Elsevier Amsterdam, 1983. p. 99-109.

CORREIA, N. Erupção Vulcânica 2014/15 - Mobilização e acolhimento da ajuda humanitária aos deslocados de Chã das Caldeiras. Seminário Nacional "Erupção Vulcânica da ilha do Fogo. Dificuldades e Lições Aprendidas”. SNPCB, Praia, 3 dejunho de 2015.

CRANDELL, D.; BOOTH, B.; KAZUMADINATA, K.; SHIMOZURU, D.; WALKER, G.; WESTERCAMP, D.Source-book for volcanic-hazards zonation. UNESCO, France, 1984.

DUNCAN, A.M.; CHESTER, D.; GUEST, J.E. Mount Etna Volcano: Environmental impact and problems of volcanic prediction. The Geographical Journal, Vol. 147, 2, 1981. p. 164-178.

DUNCAN, A.M.; DIBBEN, C.; CHESTER, D.K.; GUEST, J.E. The 1928 eruption of Mount Etna volcano, Sicily, and the destruction of the town of Mascali. Disasters, 20, 1996. p. 1-20.

GASPAR, J. L.; FERREIRA, T.; COUTINHO, R.; QUEIROZ, G.; MOTA GOMES, A. Resumo da actividade vulcânica registada na ilha do fogo (Cabo Verde) nos meses de Abril e Maio de 1995: II - História eruptiva entre 4 e 11 de Abril. IV Congresso Nacional de Geologia.Dezembro de 1995.

GASPAR, J. L.; QUEIROZ, G.; FERREIRA, T.; COUTINHO, R. A monitorização geoquímica no quadro geral da vigilância sismovulcânica da ilha do Fogo. In: RÉFFEGA, A. et al., eds.: A erupção vulcânica de 1995 na ilha do Fogo, Cabo Verde. Lisboa: Inst. Invest. Cient. Trop. (IICT),1997. p. 93-101. .
GASPAR, J.L. Ilha Graciosa (Açores): história vulcanológica e avaliação do hazard. Tese de Doutoramento no ramo de Geologia especialidade de Vulcanologia, Departamento de Geociências, Universidade dos Açores, 1996.

GRF Gabinete de Recuperação do Fogo. Governo de Cabo Verde. Memória descritiva do Fórum para a Reconstrução do Fogo - não editado. São Filipe, Fogo, 2 e 3 Março de 2015.

INE. Censo da população e habitação de 2010. Praia: Instituto Nacional de Estatísticas de Cabo Verde,2010. (Relatório inédito).

MACHADO, F.; ASSUNÇÃO, C. Carta geológica de Cabo Verde (na escala 1/100.000). Noticia explicativa da Ilha do Fogo - estudos petrográficos. Garcia de Orta 13, 4, 1965. pp. 597-604.

MONTEIRO, S., CORREIA, R. \& CUNHA, L. Riscos Naturais, Ordenamento do Território e Sociedade. Estudos de caso nas Ilhas de Santo Antão e de Santiago. $1^{\circ}$ Congresso Lusófono de Ciência Regional e $2^{\circ}$ Congresso Lusófono de Ciência Regional. Cabo Verde, Redes e Desenvolvimento Regional, 2009.

OLIVEIRA, N. Atuação do SNPCB durante as operações de evacuação, resgate de bens, segurança e monotorização da atividade vulcânica. Seminário Nacional "Erupção Vulcânica na ilha do Fogo Dificuldades e Lições aprendidas”. Praia: 03 Junho de 2015.

PDM. Caracterização e Diagnóstico do Município de Santa Catarina, ilha do Fogo. Praia: 2010.

RIBEIR0, O. A ilha do Fogo e as suas Erupções. JIU, Mem. Ser. Geográfica. no 1, 2a edição. Lisboa, 1960.

SILVA, S.; CARDOSO, N.; ALFAMA, V.; CABRAL,J.; SEMEDO, H.; PÉREZ, N.; DIONIS, S.; HERNÁNDEZ, P.; BARRANCOS, J.; MELIÁN, G.; PEREIRA, J.; FÁTIMA RODRÍGUEZ. Chronology of the 2014 volcanic eruption on the island of Fogo, Cape Verde. Geophysical Research Abstracts.Vol. 17, 2015 EGU General Assembly 2015.

SILVEIRA, A., B.; MADEIRA, J.; SERRALHEIRO, A. A estrutura da Ilha do Fogo, Cabo Verde. In: RÉFFEGA, A. et al.(Eds.) A erupção vulcânica de 1995 
na Ilha do Fogo, Cabo Verde. Lisboa: Inst. Invest. Cient. Trop. (IICT), 1997. p. 63-78.

TORRES, P.C.; MADEIRA, J.; SILVA, L.C.; SILVEIRA, A. B.; SERRALHEIRO, A.; GOMES, A. M. Carta geológica das erupções históricas da ilha do Fogo: revisão e actualização In: RÉFFEGA, A. et al.(Eds.) A erupção vulcânica de 1995 na Ilha do Fogo, Cabo Verde. Lisboa: Inst. Invest. Cient. Trop. (IICT),1997.p. 119-132

WALLENSTEIN, N. Estudo da história recente do comportamento eruptivo do Vulcão do Fogo (S. Miguel, Açores). Avaliação preliminar do hazard. Tese de Doutoramento no ramo de Geologia especialidade de Vulcanologia, Departamento de Geociências, Universidade dos Açores, 1999. 266 p.

WALLENSTEIN, N.; GASPAR, J. L.; GUEST, J.; DUNCAN, A. Estilos eruptivos observados durante a erupção vulcânica de 1995 na Ilha do Fogo, Cabo Verde. In: RÉFFEGA, A. et al. (Eds.) A erupção vulcânica de 1995 na Ilha do Fogo, Cabo Verde. Lisboa: Inst. Invest. Cient. Trop. (IICT), 1997.p. 145 - 152. 
RESUMO

A ilha do Fogo é caraterizada pela ocorrência de 27 erupções vulcânicas históricas registadas desde o seu povoamento. Neste trabalho apresenta-se a sequência dos acontecimentos ocorridos durante a erupção vulcânica de 2014/15, iniciada no dia 23 de novembro de 2014em Chã das Caldeiras (Fogo), e os seus impactos. A erupção iniciou às $9 \mathrm{~h} 45$ e foi antecedida por sismos de forte intensidade. 0 estilo eruptivo, do tipo estromboliano, iniciou com uma fase explosiva caracterizada pela libertação de gases e piroclastos (cinzas) seguida da emissão de lavas. A atividade vulcânica cessou a 8 de fevereiro, depois de ocorridos 77 dias de erupção, com a destruição das localidades de Portela, Bangaeira e Ilhéu de Losna.Apesar dasgraves repercussões socioeconómicas e ambientais, a pronta resposta à crise permitiu a evacuação eficiente das populações da Chã das Caldeiras pelas autoridades, com apoio de organismos internacionais, sem perdas de vidas humanas.

\section{PALAVRAS-CHAVE}

Erupção vulcânica. Chã das Caldeiras. Gestão da crise. Evacuação. Impactos socioeconómicos e ambientais.

\section{ABSTRACT}

Fogo Island it is characterized by the occurrence of 27 historical volcanic eruptions occurred since its settlement. This paper presents the sequence of events during the volcanic eruption of 2014/15, started on November 23, 2014 in Chã das Caldeiras (Fogo), and its impacts. The eruption started at 9:45 am and was preceded by earthquakes of strong intensity. The eruptive style, Strombolian type, began with an explosive phase characterized by the release of gases and pyroclasts (ash) followed by the emission of lavas. The volcanic activity has ceased on February 8th, after 77 days of eruption, that occurred with the destruction of the localities of Portela, Bangaeira and Ilhéu de Losna. Despite the serious socio-economic and environmental impacts, prompt response to the crisis allowed the efficient evacuation of the population of Chã das Caldeiras by the authorities, with support from international organizations, without loss of human life.

\section{KEYWORDS}

Volcanic eruption. Chã das Caldeiras. Crisis management. Evacuation. Socio-economic and environmental impacts. 
